IdeAs

Idées d'Amériques

$10 \mid 2017$

États-Unis / Cuba : une nouvelle donne?

\title{
O golpe parlamentar e o fim dasociedade salarial no Brasil
}

Ruy Braga

\section{(2) OpenEdition}

1 Journals

Édition électronique

URL : https://journals.openedition.org/ideas/2220

DOI : 10.4000/ideas.2220

ISSN : 1950-5701

Éditeur

Institut des Amériques

Référence électronique

Ruy Braga, « O golpe parlamentar e o fim dasociedade salarial no Brasil », IdeAs [En ligne], 10 | 2017, mis en ligne le 19 décembre 2017, consulté le 18 octobre 2022. URL : http://journals.openedition.org/ ideas/2220 ; DOI : https://doi.org/10.4000/ideas.2220

Ce document a été généré automatiquement le 18 octobre 2022

\section{(c) (i) () $९$}

Creative Commons - Attribution - Pas d'Utilisation Commerciale - Pas de Modification 4.0 International - CC BY-NC-ND 4.0

https://creativecommons.org/licenses/by-nc-nd/4.0/ 


\title{
O golpe parlamentar e o fim dasociedade salarial no Brasil
}

\author{
Ruy Braga
}

\section{Apresentação}

1 Não é nenhum segredo que, a partir do início da década de 2000, a ascensão do chamado "Sul global", isto é, esta região política e geográfica capaz de agregar tanto os processos de exploração nacional dirigidos pelas forças da financeirização do capital, quanto as lutas por projetos alternativos de transformação social e política, veio acompanhada de uma onda de esperanças em torno do aprofundamento da democracia e da mitigação das desigualdades sociais. Em grande medida, o aumento das expectativas, sobretudo em relação aos países da América do Sul, mas, igualmente, a África do Sul, a Índia e a Turquia, por exemplo, deveu-se a uma peculiar combinação de vitórias eleitorais de forças sociais esquerdistas, crescimento econômico e multiplicação de protestos contra a espoliação do bem comum.

2 Se bem é verdade que, como afirma Vijay Prashad, o Sul global é “(...) um mundo de protestos, um furacão de atividades criativas, capaz de produzir uma abertura cuja direção política não é fácil de definir" (Prashad, 2012: 18), tornou-se cada dia mais claro que a crise da globalização iniciada em 2008 fez refluir o otimismo original, substituindo-o pelo medo do recrudescimento do autoritarismo e do aprofundamento da segregação social. A grande recessão econômica que acompanhou o início da atual crise não apenas desorganizou os arranjos hegemônicos nacionais construídos durante décadas de mobilizações contra a exploração e a dominação, como colocou no centro do palco da política mundial o desafio da combinação entre acumulação econômica e legitimação política.

De fato, a partir de 2008, é possível perceber, em especial,no Sul global, o acúmulo das tensões sociais derivadas da necessidade dos Estados nacionaisestimularem o crescimento em um contexto recessivo eassegurarem a unidade das classes dominantes por meio da promoção de um nacionalismo reacionário, enquanto respondem 
violentamente ao avanço das formas mais ou menos inorgânicas de resistência popular. A reprodução do conflito entre acumulação e legitimação tem fortalecido tanto a financeirização do capital, a espoliação do trabalho e o crescimento lento sem a criação de empregos, quanto estimulado o nacionalismo, o autoritarismo e a corrupção estatal em uma escala sem precedentes.

\section{A sociedade brasileira na crise da globalização}

4 Por sua vez, o ataque global aos direitos sociais e ao bem comumtem sido enfrentado por táticas políticas contingentes, forças populares ainda em formação e coalizões programaticamente instáveis. Trata-se de um embate desigual entre um Estado acólito das finanças e uma resistência popular fragmentada cujo resultado mais visível até o momento foi o agudo estreitamento do espaço político assegurado pela repressão aos movimentos sociais, pela despolitização dos conflitos via estímulo ao consumo, pela cooptação de dirigentes das forças antagonistas epela erosão do espaço público. Quer estejamos falando da China, da Índia, da África do Sul, da Turquia ou da América Latina, o cenário repete-se: o choque entre a acumulação e a legitimação semeia o autoritarismo e a desesperança.

5 Aqui, vale lembrar que a informalização do trabalho acompanhada pelo estímulo governamental ao empreendedorismo dos subalternos, uma maneira de transformar o vício em virtude, tende a reforçar os efeitos deletérios deste choque. Afinal, em um contexto de erosão em escala mundial dos rendimentos do trabalho, as expectativas populares estimuladas pela ideologia do empreendedorismo fatalmente irão se frustrar tendo em vista o estreitamento dos mercados nacionais. O chamado capitalismo de plataforma não pode substituir a promessa da inclusão social via trabalho subjacente à sociedade salarial exatamente porque não ser capaz de estabilizar minimamente a condição proletária. Antes, trata-se de uma generalização da lógica da competição entre as classes subalternas afinada com o polo da acumulação, mas, completamente divorciada do polo da legitimação. Assim, a "uberização" do trabalho pode bem reforçar as pulsões populistas de direita que têm semeado a segregação social em diferentes contextos nacionais.

6 Apesar de ter chegado um pouco mais tarde na crise da globalização, a sociedade brasileira tem experimentado, desde o golpe parlamentar de 2016, um desmanche sem precedentes do projeto democrático social construído entre os anos 1940 e 1980. Tratase do desaparecimento de um horizonte político, ou seja, da promessa da cidadania salarial no país. Portanto, a combinação entre o surgimento da proteção trabalhista e a ampliação dos direitos sociais com recursos assegurados constitucionalmente não apenas estimulou a industrialização do país, como também assegurou às classes subalternas brasileiras um patamar, ainda que mínimo, de bem-estar social. Para milhões de trabalhadores pobres e vivendo em condições precárias de vida ou de trabalho, a existência da Consolidação das Leis Trabalhistas (CLT) e da previdência social acalentava o sonho de um futuro melhor. ${ }^{1}$

7 Os efeitos sociais do desaparecimento deste horizonte político ainda não foram plenamente percebidos no país. Os ataques aos alicerces da cidadania salarial, isto é, a proteção trabalhista e previdenciária, ainda não se fizeram sentir por completo. Tratase de um processo que levará ainda um par de anos para revelar todo seu potencial desagregador. No entanto, quando isso acontecer, o nível de ressentimento popular 
deverá se tornarcrítico. Afinal, as contrarreformas pós-impeachment estão desmantelando os principais instrumentos de redistribuição de renda do país, isto é, a previdência social e a CLT.

8 Ainda assim, enganam-se aqueles que imaginam que as contrarreformas relacionam-se apenas à trajetória da renda nacional. Os direitos sociais e a luta por sua efetivação deram forma a um inédito e legítimo espaço de disputas políticas que historicamente foi ocupado pelas classes subalternas nacionais. Afinal, foi o processo de ampliação da cidadania salarial que cimentou o consentimento das massas populares em relação ao Estado burguês no país. A partir, sobretudo, dos anos 1930, as greves e protestos sociais relacionados ao tenentismo e à criação do Partido Comunista do Brasil aprofundaram uma crise de hegemonia a qual o Estado Novo, isto é, a ditadura instaurada por Getúlio Vargas a partir de 1930, respondeu por meio de concessões protetivas aos trabalhadores. A regulamentação da jornada de trabalho e a lei do salário mínimo foram, aos poucos, consolidando-se após a promulgação da CLT em 1943.

\section{O desmanche da sociedade salarial no Brasil}

9 Tratou-se de um ciclo histórico de construção de um espaço legitimado pelo Estado para o conflito entre as classes no país. A "questão social" deixava, pela primeira vez na história brasileira, de ser tratada como um "caso de polícia". Nas décadas de 1950 e 1960, consolidou-se uma identidade classista nacional que açambarcou o conjunto da classe trabalhadora, quer estivesse empregada na indústria fordista ou não. O"trabalhador nacional" tornou-se uma imagem central da cena política do país, protagonizando greves e garantindo o apoio a governos comprometidos com o esforço de industrialização nacional. A construção da sociedade salarial no Brasil, ainda que frágil e problemática, foi o fator chave para a superação da crise de hegemonia na qual o país encontrava-se inserido desde a década de $1920 .^{2}$

10 A centralidade desse processo de construçãosocial era tão pronunciada que nem mesmo o golpe civil-militar do $1^{\circ}$ de abril de 1964 foi capaz de alterar substantivamente, apesar dos interesses empresariais, a CLT, limitando-se, em 1966, a substituir a lei da estabilidade no emprego para aqueles que superassem 10 anos de trabalho pela criação do Fundo de Garantia por Tempo de Serviço (FGTS). Da mesma forma, a despeito de pequenas alterações na legislação trabalhista ocorridas nos anos 1970 que flexibilizou a contratação de força de trabalho em setores de apoio, como os vigias e seguranças, por exemplo, a democratização do país associado à intensificação do ciclo grevista nos anos 1980 redundou no coroamento da proteção do trabalho na forma do capítulo dos direitos sociais da Constituição de 1988.

11 A partir de então, a nova Constituição promoveria os direitos sociais e trabalhistas, elevando a proteção nacional das classes subalternas para um patamar inédito na história brasileira por meio, sobretudo,da criaçãodo Sistema Único de Saúde, além de definir fontes tributárias estáveis para os gastos sociais e para os investimentos em educação. Nem mesmo o colapso do modelo de desenvolvimento nacionaldesenvolvimentista no final dos anos 1980 e duas décadas de hegemonia neoliberal estabelecida no país a partir do Plano Real, em fevereiro de 1994, foram capazes de impedir que a dinâmica da afirmação de direitos sociais por meio de lutas sociais democratizantes refluísse de maneira significativa. 
12 Durante os governos Lula da Silva e Dilma Rousseff, apesar da manutenção do tripé macroeconômico neoliberal - formado por uma combinação entre as taxas de juros elevadas, câmbio flutuante e independência operacional do Banco Central -, houve aumento real do gasto social, ampliação da formalização do mercado de trabalho e investimentos em educação, algo que se alinhava, em linhas gerais, ao fluxo democratizante dos anos 1980. Na realidade, entre idas e vindas, é válido dizer que, o ciclo histórico marcado pela construção de uma sociedade salarial no país estendeu-se dos anos 1930 até 2016 sem enfrentar grandes contratempos. Este quadro mudou dramaticamente com o advento do golpe de 17 de abril de 2016.

13 A partir de então, aprovou-se um teto constitucional para os gastos públicos que atinge severamente os gastos sociais, sem alterar o principal gasto do governo federal que é sua conta de juros e de amortizações da dívida pública. Além disso, aprovou-se uma lei que permite a universalização da terceirização e uma contrarreforma da CLT que, em termos práticos, elimina a promessa da sociedade salarial para a imensa maioria dos trabalhadores brasileiros. Além de permitir a generalização do trabalho terceirizado e intermitente, atinge mortalmente a função dos sindicatos no país de fiscalizarem o respeito aos direitos trabalhistas pelas empresas por meio do princípio do negociado sobre o legislado, a contrarreforma votada pelo congresso nacional no dia 11 de julho de 2017 permite incontáveis formas de flexibilização da jornada de trabalho, colocando um ponto final naquele ciclo protetivo que, historicamente, iniciou-se há exatos 100 anos, com a greve geral do junho-julho de 1917 na cidade de São Paulo.

14 Agora, o congresso prepara-se para ampliar o tempo de contribuição para a aposentadoria, diminuir o valor das pensões e dificultar o acesso aos benefícios sociais pagos pelo sistema previdenciário. Muito provavelmente, o governo de Michel Temer conseguirá aprovar a contrarreforma da previdência, apesar de sua natureza antipopular e custosa em termos de apoio eleitoral. Caso obtenha êxito nesta empreitada, um governo ilegítimo e ultra-neoliberal terá conseguido realizar em dois anos aquilo que uma ditadura seguida por governos neoliberais moderados não forma capazes: sepultar a promessa da cidadania salarial, eliminando o polo protetivo e fazendo ruir um dos pilares centrais da legitimação do regime político no país. Sem a CLT e a aposentadoria, que tipo de legitimação os governos imaginam poder conquistar numa sociedade onde praticamente todas as dimensões do bem comum já foram mercantilizadas?

$15 \mathrm{Na}$ realidade, no lugar da cidadania salarial, assistiremos à universalização dos mecanismos típicos do capitalismo de plataforma que, na atual etapa tecnológica, servirão para reinventar mais uma vez os dilemas de nosso atraso social. Para avaliar melhor o significado histórico das contrarreformas pós-impeachment, talvez fosse útil uma rápida comparação com a África do Sul pós-apartheid. Também lá, uma onda de esperanças populares adveio da derrota do regime racista por uma sociedade civil mobilizada e liderada pelo Congresso Nacional Africano (ANC). No entanto, um verdadeiro Thermidor neoliberal seguiu-se à libertação política dos negros, aprofundando as desigualdades e, sub-repticiamente, reintroduzindo a segregação social, agora não mais baseada na cor da pele, mas no poder do dinheiro. 0 mercado de trabalho foi ainda mais informalizado e os empregos desapareceram, deixando um saldo de desempregados acima de $30 \%$ da PEA. ${ }^{3}$

16 O apartheid racial foi sucedido peloapartheid social e a segregação dos negros e dos pobres não se alterou significativamente. A escalada de violência social e xenofóbica 
vivida pelo país desde o início da crise da globalização revela como, na expressão de Chico de Oliveira, o "globalitarismo neoliberal" conduz à desintegração da sociedade. ${ }^{4}$ Para assegurar a reprodução da ordem, segue-se um recrudescimento do autoritarismo estatal. 0 massacre dos mineiros ocorrido em agosto de 2012 no povoado de Marikana sintetizou tragicamente estas tensões sociais, anunciando aos trabalhadores negros que qualquer expectativa relacionada à cidadania salarial deveria ser eliminada de seu horizonte político. A partir de então, a relação entre os trabalhadores e o Estado passou a ser mediada pela gramática da violência social.

\section{Considerações finais}

Não há dúvidas de que, se o desmanche da sociedade salarial brasileira continuar avançando no ritmo atual, em breve, assistiremos a uma escalada semelhante. Sem o horizonte da proteção trabalhista e sem perspectivas de aposentadoria, os subalternos irão se perceber aprisionados em um espaço tão restrito de ação política que fará da desesperança a regra, divorciando litigiosamente as massas populares do Estado. 0 caminho contrarreformista e anti-popular escolhido por um governo ilegítimo é, não apenas economicamente ruinoso por atacar frontalmente os rendimentos daqueles que vivem do trabalho, como, politicamente suicida por erodir as bases institucionais da legitimidade do Estado.

O resultado da atual crise brasileira talvez seja o nascimento de uma sociedade tão desigual e violenta que não seja capaz de reconhecer a ilegitimidade de seus dirigentes. Os exemplos de Recep Erdoğan na Turquia, de Narendra Modi na Índia ou de Rodrigo Duterte nas Filipinas, servem de alerta: a crise da globalização fechou subitamente a janela de oportunidades para o progresso do Sul global, alçando o autoritarismo ao primeiro plano da cena política. Populismos direitistas multiplicam-se pelo mundo afora, alimentando-se da frustração das expectativas populares em relação ao futuro. No nosso caso, oatual desmanche da cidadania salarial é o combustível que alimenta a fogueira. Reverter esta situação exigirá o melhor das forças dos democratas.

\section{BIBLIOGRAPHIE}

Antunes, Ricardo. 0 continente do labor.São Paulo: Boitempo, 2011.

Barchiesi, Franco. Precarious Liberation:Workers, the State, and Contested Social Citizenship in Postapartheid South Africa. Nova Iorque: State University of New York Press, 2011.

Cardoso, Adalberto. A construção da sociedade do trabalho no Brasil: uma investigação sobre a persistência secular das desigualdades.Rio de Janeiro: FGV, 2010.

Oliveira, Francisco de. Quem canta de novo L'Internationale? Em Boaventura de Sousa Santos (org.), Trabalhar o mundo: os caminhos do novo internacionalismo operário. Rio de Janeiro: Civilização Brasileira, 2005. 
Prashad, Vijay. The Poorer Nations: A Possible History of the Global South. Londres: Verso, 2012.

\section{NOTES}

1. Para mais detalhes, ver Adalberto Cardoso, A construção da sociedade do trabalho no Brasil: uma investigação sobre a persistência secular das desigualdades(Rio de Janeiro, FGV, 2010).

2. Para mais detalhes, ver Ricardo Antunes, 0 continente do labor (São Paulo, Boitempo, 2011).

3. Ver Franco Barchiesi, Precarious Liberation:Workers, the State, and Contested Social Citizenship in Postapartheid South Africa (Nova Iorque, State University of New York Press, 2011).

4. Francisco de Oliveira, Quem canta de novo L'Internationale? Em Boaventura de Sousa Santos (org.), Trabalhar o mundo: os caminhos do novo internacionalismo operário (Rio de Janeiro, Civilização Brasileira, 2005).

\section{AUTEUR}

\section{RUY BRAGA}

Departamento de Sociologia da Universidade de São Paulo (USP) 